\title{
Conceitos e práticas pedagógicas dos professores unidocentes diante das dificudades de aprendizagem em matemática
}

\section{Concepts and pedagogical practices of unidocente teachers facing learning difficulties in mathematics}

DOI: $10.46814 / \operatorname{lajdv3n6-027}$

Recebimento dos originais: 01/11/2021

Aceitação para publicação: 15/12/2021

\section{Janíbia Fernanda Costa de Oliveira}

Mestre em Educação pelo PPGE/IE/UFMT. Professora Formadora do Centro de Formação e Atualização dos Profissionais da Educação Básica - CEFAPRO/CUIABÁ. Secretaria de Estado de Educação de Mato Grosso

E-mail: janibia12@gmail.com

\section{Marta Maria Pontin Darsie}

Doutora em Educação pela USP. Professora Doutora do Programa de Pós Graduação em Educação da Universidade Federal de Mato Grosso (PPGE/UFMT).

E-mail: marponda@uol.com.br

\section{RESUMO}

$\mathrm{O}$ artigo tem o objetivo de apresentar, resultados de uma pesquisa de mestrado desenvolvida no Programa de Pós-Graduação da Universidade Federal de Mato Grosso. Na investigação procuramos compreender quais são as concepções e as práticas docentes diante das dificuldades de aprendizagem em matemática de alunos dos 4os anos do Ensino Fundamental. Neste trabalho faremos um recorte de nosso estudo, divulgando apenas os resultados das concepções de professores referentes às dificuldades de aprendizagem e dificuldades de aprendizagem em matemática. A investigação foi desenvolvida em dois momentos: no primeiro fizemos um levantamento de pesquisas brasileiras que discutiam as dificuldades de aprendizagem em matemática com o propósito de conhecer o quê os autores dizem sobre o tema. Segundo, realizamos a pesquisa de campos, com seis professoras que lecionam matemática em turmas de $4^{\circ}$ ano do ensino fundamental, em três escolas da rede estadual de Cuiabá Mato Grosso. Em resposta a problemática de nosso estudo, concluímos que todos os sujeitos transitam, maior ou menor grau, entre duas perspectivas distintas de Educação Matemática. Assim, é possível dizer que para dois sujeitos há uma tendência à perspectiva contemporânea, enquanto outros, há uma convergência para a perspectiva tradicional. Quanto às suas práticas, encontramos uma forte tendência para as concepções tradicionais

Palavras chave: Concepções, Dificuldades de Aprendizagem e Dificuldades de Aprendizagem em Matemática.

\begin{abstract}
This article aims to present the results of a master's research developed in the Graduate Program of the Federal University of Mato Grosso. In the research, we tried to understand what are the conceptions and the teaching practices regarding the learning difficulties in mathematics of 4th grade elementary school students. In this paper we will make a cut of our study, disclosing only the results of the conceptions of teachers regarding learning disabilities and learning difficulties in mathematics. The
\end{abstract}


research was developed in two stages: first, we did a survey of Brazilian research on learning disabilities in mathematics with the purpose of knowing what the authors say about the subject. Second, we conducted field research with six teachers who teach mathematics in 4th grade classes in three public schools in Cuiabá, Mato Grosso. In response to the problematic of our study, we concluded that all subjects move, to a greater or lesser degree, between two different perspectives of Mathematics Education. Thus, it is possible to say that for two subjects there is a tendency to the contemporary perspective, while others, there is a convergence to the traditional perspective. As for their practices, we found a strong tendency towards traditional conceptions

Keywords: Conceptions, Learning Disabilities and Learning Difficulties in Mathematics.

\section{INTRODUÇÃO}

Este artigo é um recorte de uma pesquisa de mestrado que teve como objetivo compreender as concepções e as práticas dos professores unidocentes referentes às dificuldades de aprendizagem em matemática dos alunos ${ }^{1}$ das turmas do $4^{\circ}$ ano do Ensino Fundamental das Escolas da Rede Estadual de Cuiabá - Mato Grosso. Para este momento nosso diálogo estará direcionado apenas nas concepções dos professores sobre alunos que são diagnosticados em situação de Dificuldades de Aprendizagem em Matemática.

Considerando a natureza de nossa pesquisa, o método de investigação adotado se insere no paradigma da abordagem qualitativa de cunho interpretativo. Para a construção do referencial metodológico nos embasamos em Bogdan e Biklen (1994); Baraldi (1999); Fiorentini e Lorenzato (2006); Ludke e André (1986); Triviños (1987).

Inicialmente realizamos um mapeamento para identificar as pesquisas que discutem as dificuldades de aprendizagem, observamos que alguns trabalhos focavam no ensino, outros abordavam o desenvolvimento da aprendizagem escolar dos alunos, e ainda outras pesquisas que analisavam as políticas educacionais. Porém, apenas um número bastante reduzido estudava o fracasso escolar na perspectiva da aprendizagem, ou seja, o desenvolvimento da aprendizagem escolar dos alunos. Diante da escassez de pesquisas encontradas e na intenção de contribuir para a construção do conhecimento científico é que propusemos realizar tal investigação.

Mediante o referencial teórico utilizado e dos dados coletados, estabelecemos como categorias de análise de um lado a Perspectiva Contemporânea de Educação Matemática e de outro lado a Perspectiva Tradicional do Ensino de Matemática. O quadro abaixo resume o que entendemos por tais perspectivas

\footnotetext{
${ }^{1}$ Utilizaremos os termos alunos, estudantes, educandos como sinônimos.
} 


\begin{tabular}{|c|c|c|}
\hline Concepções & $\begin{array}{l}\text { Perspectiva Tradicional do Ensino de } \\
\text { Matemática }\end{array}$ & $\begin{array}{l}\text { Perspectiva Contemporânea de Educação } \\
\text { Matemática }\end{array}$ \\
\hline 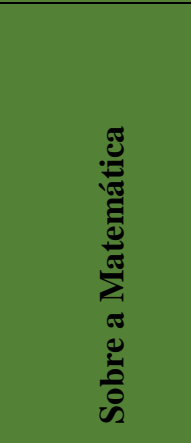 & $\begin{array}{l}\text { Caracteriza-se por uma visão estática, a } \\
\text { histórica e dogmática das ideias } \\
\text { matemáticas, sendo elas obtidas por } \\
\text { descoberta. O conhecimento matemático } \\
\text { emerge do mundo físico e é extraído pelo } \\
\text { homem através dos sentidos, ou a } \\
\text { matemática é autossuficiente sendo } \\
\text { inteiramente desvinculada do mundo físico. } \\
\text { Portanto, ênfase na matemática pela } \\
\text { matemática, sendo ela neutra e sem } \\
\text { interesses sociais e políticos. }\end{array}$ & $\begin{array}{l}\text { A matemática é uma construção humana } \\
\text { sendo formada por estruturas e relações } \\
\text { abstratas entre formas e grandezas reais e } \\
\text { possíveis. O conhecimento matemático é um } \\
\text { saber prático, relativo, dinâmico, não } \\
\text { universal e, portanto, produzido } \\
\text { historicamente nas mais várias práticas } \\
\text { sociais. }\end{array}$ \\
\hline 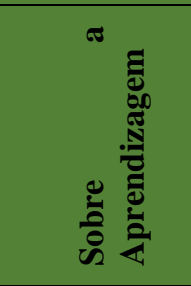 & $\begin{array}{l}\text { O aluno aprende através de um processo de } \\
\text { repetição, ou seja, aprende reproduzindo } \\
\text { linguagem e raciocínios lógicos- } \\
\text { matemáticos ditados pelo professor. }\end{array}$ & $\begin{array}{l}\text { A apreensão se dá de forma operativa e na } \\
\text { interação, a partir de abstrações reflexivas. O } \\
\text { processo de aprendizagem se efetiva } \\
\text { mediante o entendimento da maneira de } \\
\text { pensar e o modo de saber dos educandos. O } \\
\text { aluno aprende, atribuindo sentido e } \\
\text { significado às ideias matemáticas. }\end{array}$ \\
\hline
\end{tabular}

Fonte: Brunelli (2012).

Apresentaremos neste artigo o que se define como dificuldades de aprendizagem e suas possíveis causas, fundamentados em diferentes autores. Destacaremos também os aspectos observados no diagnóstico das dificuldades de aprendizagem, considerando que estas, podem ser desencadeadas por fatores orgânicos, específicos, emocionais e ambientais. Além disso, explicitaremos a concepção de dificuldades de aprendizagem definida em nossa pesquisa. Apresentaremos ainda, as concepções dos professores sobre as dificuldades de aprendizagem em matemática.

\section{APORTE TEÓRICO}

\subsection{CONSIDERAÇÕES SOBRE DIFICULDADES DE APRENDIZAGEM}

Quando a educação escolar, no século XIX passar a ser priorizada como direito de "todos" e os esforços focam na ampliação de sua oferta e abrangência, os professores se deparam com problemas relacionados às diferenças em sala de aula. Surgem dificuldades em entender e explicar como se davam os processos de desenvolvimento e da aprendizagem dos alunos, pois estes respondiam de modo distinto quando apresentados às atividades propostas pelo professor em sala de aula. Assim, os 
professores passaram a utilizar conceitos e métodos das ciências biológicas e da medicina para tentar explicar essas diferenças.

Diante isso, as instituições escolares passaram a procurar explicação para as diferenças dos rendimentos escolares por meio de avaliações de aptidão. "O pensamento pedagógico brasileiro, na primeira metade do século, foi marcado pela publicação de dezenas de obras sobre medidas objetivas de ensino e sobre testes mentais" (TIBALII, 1998, p.45).

A literatura sobre dificuldades de aprendizagem, por abranger diferentes áreas do conhecimento (medicina, psicologia, linguística, educação, etc.) apresenta uma variedade de definições e nomenclaturas. O termo dificuldade de aprendizagem surgiu com o Dr. Samuel Kirk, em 1962 (GARCÍA, 1998, p.69), pois a partir desta década se classificam as dificuldades de aprendizagem ocasionadas por danos cerebrais. Anterior a essa época as crianças eram consideradas como retardadas mentais, transtornadas emocionalmente ou em desvantagem cultural. Assim, o termo era entendido como desordens significativas que interferiram na compreensão de algo pelo indivíduo.

Autores como Smith e Strick (2001); Sanchez (2004); Coll, Palácio e Marchesi (1995) utilizam o termo dificuldade de aprendizagem para referir-se, não só a distúrbios, mas também para entender a dificuldade de aprendizagem como qualquer dificuldade observável no aluno em acompanhar o ritmo de aprendizagem de sua turma. Inclui problema de comportamento, emocional, neurológico, podendo ter vários fatores associados.

Podemos observar na literatura que além da utilização do termo distúrbio, é possível encontrar transtorno de aprendizagem, problemas escolares e até mesmo fracasso escolar, ora distinto ou como sinônimo de dificuldade de aprendizagem. Portanto, consideramos relevante pontuarmos o que entendemos por esses termos, já que percebemos como manifestações diferentes do que entendemos como dificuldades de aprendizagem.

Consideramos que problemas escolares não são inerentes à criança, se manifestam devido à própria organização curricular e metodológica. A criança apresenta dificuldade para desenvolver determinas atividades, ora porque o conteúdo está além de suas condições (psicológicas, biológicas, emocionais, culturais), ora porque a instrução está inadequada. Quando a criança tem acesso a outro tipo de organização do ensino, rapidamente avança em suas aprendizagens.

No que tange aos distúrbios e transtornos de aprendizagem adotamos a definição de Correia e Martins (1999); Almeida e Col (1995); Corsini (1998). Estes autores relatam que tais distúrbios e transtornos ocorrem com as crianças que têm dificuldades para aprender por apresentarem algum comprometimento biológico ou neurológico, ordem orgânica.

É fácil encontrarmos no meio educacional, profissionais que consideram que o aluno tem dificuldade de aprendizagem. Sobretudo, dizer que o aluno tem dificuldade de aprendizagem parece 
atribuir ao aluno portador de algo, como na medicina que se diz que o paciente tem uma doença. Preferimos defender que o aluno está momentaneamente em dificuldade de aprendizagem em determinada área do conhecimento e/ou conteúdo.

Respaldamo-nos em Charlot (1997 apud CHABANNE, 2006, p. 17) ao dizer-nos que esse intervalo em que o aluno está com dificuldade pode ser entendido como um tempo "de experiência que o aluno vive e interpreta", esta dificuldade então resume-se e a um estado momentâneo na aprendizagem do aluno.

Seguindo essa compreensão de dificuldade de aprendizagem, estas podem estar associadas a problemas familiares, emocionais, escolares, etc., mas também podem ter origem a partir do contexto escolar, como as atividades inadequadas propostas pelo professor ou, estão associadas às lacunas conceituais que se constituem no decorrer de anos de estudo. Assim, em um dado momento o aluno por não ter aprendido determinados conceitos começa então a apresentar dificuldades para estabelecer relações mais complexas.

Nesse contexto, o fracasso escolar, que muitas vezes é confundido com dificuldade de aprendizagem "define a distância entre o nível das competências pressupostas de um aluno e o nível das competências definido como 'normal'." (CHABANNE, 2006, p.16), sendo desencadeado por um acúmulo de situações envolvidas que corroboram para a parada na aprendizagem escolar do aluno. O que não quer dizer que esteja irreversível.

Cada aluno possui traços de personalidades que lhe são particulares, e os modos em que as dificuldades de aprendizagem costumam se apresentar está vinculada a individualidade de quem aprende; por isso, não se pode falar em razões que sejam exclusivamente responsáveis ou tratamentos semelhantes que condicionam; é inadequado e incorreto determinar que haja uma criança disléxica, mas sim uma criança que apresenta dislexia. Em contrapartida, as ações sofridas pela criança durante a aprendizagem devem ser consideradas, pois apontam as diferenças existentes entre cada uma, seja pela sua composição biológica, suas reações emocionais ou sem ambiente social. Devido a isso, é fundamental conhecer o aluno detalhadamente, ou seja, observá-lo por completo, buscar compreender seus problema peculiares, fazê-lo perceber suas virtudes e os pontos em que deve melhorar, além de engendrar sistemas que o auxiliem na obtenção de êxitos em sua aprendizagem.

Mesmo assim, as dificuldades de aprendizagem permanecem. No entanto, a criança desenvolve recursos que permitem neutralizar as perdas com ganhos, e, assim, equilibrar suas dificuldades com prósperos resultados, se for devidamente orientada ou assistida pela escola, família e outras instituições relacionadas. 
A intervenção pedagógica abarca uma série de métodos de auxílio à criança, então quanto mais cedo ocorrer, melhor já que assim o estudante poderá aprender a lidar com mais facilidade com sua dificuldade em aprender.

\subsection{CONSIDERAÇÕES ACERCA DAS DIFICULDADES DE APRENDIZAGEM EM MATEMÁTICA}

Vale ressaltar neste momento que a nossa pesquisa teve como propósito específico investigar as dificuldades de aprendizagem em matemática. A maneira como esta disciplina é concebida no âmbito educacional por certo implicará na forma como deverá ser ensinada e, por conseguinte, aprendida. Portanto, concebemos que a matemática não é uma ciência inalterada e imóvel; pois recebe influências de outras áreas de conhecimento. Ademais, a própria definição de matemática se transforma com o passar do tempo. Assim, a matemática não pode ser vista como uma disciplina fechada, pronta, da mesma natureza, abstrata ou desprendida da realidade. No decorrer do tempo, ela esteve anexada às áreas diversificadas do conhecimento, respondendo a infinitas questões e necessidades do homem, auxiliando-o como mediadora da compreensão do mundo que o cerca.

Entretanto, mesmo diante desta "nova" forma de entender a matemática, observamos que alguns educadores ainda insistem na proposta de um ensino tradicional, obsoleto e sem significado para os estudantes. Essa postura de alguns docentes contribui para que os discentes tenham dificuldades de aprendizagem em matemática e, como resultado, na maioria das vezes, são retidos, ou então, mesmo que promovidos, têm dificuldades de empregar o conhecimento "adquirido". Em resumo, não obtém verdadeiramente acesso a esse saber, que é fundamentalmente importante.

Quando o assunto é dificuldade de aprendizagem em Matemática, muitos dizem que esta é uma disciplina complexa e que acabam não se identificando com ela. Mas essas dificuldades podem ocorrer não só pelo fato de não gostar ou por achar um tanto complexa, mas sim por fatores mentais, pedagógicos e psicológicos, que desencadeiam uma série de conceitos e trabalhos que necessitam ser desenvolvidos ao se trabalhar sobre dificuldades em qualquer área, como na Matemática.

É relevante realçar que a dificuldade de aprendizagem em matemática estimula poderosa sensação de aceitação ou de repúdio. Diversos alunos, por causa de um passado de fracassos em Matemática, creem que são incapazes, e como consequência disso, são levados a desenvolverem uma baixa estima.

Ao tratar da origem das dificuldades de aprendizagem em Matemática (DAM), observa-se que existem muitas dúvidas, e que não existe uma única causa que possa ser justificada, mas sim várias em conjunto. As causas das dificuldades podem ser observadas nos alunos ou quando se refere ao modo de ensinar a Matemática. 
Confiamos que o papel fundamental do professor é auxiliar os alunos a ter afeção com a Matemática e a construírem sua autoestima positiva e que analisando alguns motivos das dificuldades de aprendizagem em Matemática, alcancem resultados superiores no ensino dessa disciplina.

Quanto aos alunos, são considerados os fatores responsáveis pelas diferenças na execução matemática, a memória, a atenção, a organização espacial, a atividade perceptivo-motora, a falta de consciência, habilidades verbais, as falhas estratégicas.

Sanchez (2004) destaca que as dificuldades de aprendizagem em Matemática podem ser observadas nos seguintes aspectos:

Dificuldades em relação ao desenvolvimento cognitivo e à construção da experiência matemática; do tipo da conquista de noções básicas e princípios numéricas, da conquista da numeração, quanto à pratica das operações básicas, quanto a mecânica ou quanto à compreensão do significado das operações. Dificuldades na resolução de problemas, o que implica a compreensão do problema, compreensão e habilidade para analisar o problema e raciocinar matematicamente.

Dificuldades quanto às crenças, às atitudes, às expectativas e aos fatores emocionais acerca da matemática. Questões de grande interesse e que com o tempo podem dar lugar ao fenômeno da ansiedade para com a matemática e que sintetiza o acúmulo de problemas que os alunos maiores experimentam diante do contato com a matemática.

Dificuldades relativas à própria complexidade da matemática, como seu alto nível de abstração e generalização, a complexidade dos conceitos e algoritmos. A hierarquização dos conceitos, o que implica ir assentando todos os passos antes de continuar, o que nem sempre é possível para muitos alunos, a natureza lógica e exata de seus processos, algo que fascinava os pitagóricos, dada sua harmonia e sua "necessidade", mas que se torna muito difícil para certos alunos; a linguagem e a terminologia utilizadas, que são precisas, que exigem uma captação (nem sempre alcançada por certos alunos), não só do significado, como da ordem e da estrutura em que se desenvolve.

Dificuldades originadas no ensino inadequado ou insuficiente, seja porque à organização do mesmo não está bem seqüenciado, ou não se proporcionam elementos de motivação suficientes; seja porque os conteúdos não se ajustam às necessidades e ao nível de desenvolvimento do aluno, ou não estão adequados ao nível de abstração, ou não se treinam as habilidades prévias; seja porque a metodologia é muito pouco motivadora ou muito pouco eficaz. (p.174).

Sadovsky (2007, p. 15) ressalta que o desempenho inferior dos alunos na matemática não é uma realidade apenas do Brasil. Atualmente, a educação matemática sintetiza-se em normas mecânicas ofertadas na escola, onde o aluno não visualiza sua utilização em seu cotidiano. Há carência de formação de professores para examinar profundamente os aspectos mais indispensáveis, os quais facilitam considerar os conhecimentos prévios dos alunos, as situações problema e os recentes conhecimentos a desenvolver.

Temos consciência que antes mesmo da criança ser inserida na escola, ela já tem em si algumas noções de matemática e números. Até mesmo as crianças de classes economicamente mais baixas, sabem pelo menos responder sua idade, identificando os números com os dedos das mãos, algumas 
vezes tem noção de dinheiro. Logo, quando o professor desempenha seu papel de intermediador de conhecimentos, deve anexar em suas atividades as competências que os alunos trazem consigo.

É fundamental educar desde os anos iniciais, considerando o raciocínio lógico e dedutivo das crianças, de maneira que os conhecimentos sejam assimilados como parte espontânea da linguagem e do pensar do dia a dia, como algo fundamental para o crescimento intelectual. Diante disso, o professor necessita incentivar a criatividade, demonstrando que a matemática é uma área que está se movimentando incessantemente como uma obra que necessita de alterações e adequações. Portanto, para fomentar a criatividade, o professor precisa propor atividades que desafiem as crianças, que sejam significativas; o professor também deve propor problemas com situações reais, tendo por objetivo modificar o próprio aluno para que ele se sinta confiante frente aos conhecimentos manipulados durante os estudos.

É comum culpar o professor dos anos iniciais pelas deficiências nos conhecimentos matemáticos. Por sua vez, estes educadores se justificam declarando que a matemática não é sua especialidade. A averiguação dessas deficiências pode ser comprovada pela maneira como é ministrada tal disciplina nessa fase da vida escolar, influenciando futuramente na execução de um bom ou ruim desempenho nesta área pela criança. Frente a esse ponto de vista, podem ser vistos os resultados alcançados pelos alunos nas avaliações de rendimento na disciplina, a forma de como se dá o ensino desse componente curricular.

Em face de tantas sensações negativas que a matemática propicia a criança, adicionado ao bloqueio em não subjugar sua linguagem e não possuir aproximação ao seu conhecimento, daí vem a sensação de fracasso escolar nessa disciplina.

Segundo Vitti,

O fracasso do ensino de matemática e as dificuldades que os alunos apresentam em relação a essa disciplina não é um fato novo, pois vários educadores já elencaram elementos que contribuem para que o ensino da matemática seja assinalado mais por fracassos do que por sucessos (VITTI, 1999, p.19).

A conquista da consciência relacionada à dificuldade de aprendizagem em matemática é antiga. Deriva da forma como o conteúdo é apresentado ao aluno em cada faixa etária. Na fase operatória, a transição do concreto para o abstrato, o aluno pode defrontar-se com obstáculos ao realizar os exercícios propostos pelo professor, onde compreenderia melhor o processo de adição, contando bolinhas de gude ou qualquer material manipulável. No entanto, se é exercitado apenas o cálculo mecanicamente por questão de memorização, a criança não obtém conhecimentos prévios para dar sequência aos estudos. 
Por conseguinte, o professor necessita levar em consideração os conhecimentos prévios formais e informais que os alunos trazem das fases anteriores, para planejar a sua ação pedagógica de forma que as crianças explanem a própria capacidade para desenvolver conhecimentos matemáticos. Conforme os Parâmetros Curriculares Nacional (PCN), o professor ao planejar e realizar a gestão da sala de aula precisa

Estimular os alunos a buscar explicações e finalidades para as coisas, discutindo questões relativas à utilidade da Matemática, como ela foi construída, como pode construir para a solução tanto de problemas do cotidiano como de problemas ligados à investigação científica. Desse modo, o aluno pode identificar os conhecimentos matemáticos como meios que auxiliam a compreender e atuar no mundo (PCN, 1997, p.62 - 63).

Demarcaremos como algebrista aquele ou aquela que tem por apego apenas a parte algébrica pura da matemática, não tem vontade em ir atrás, por hora, da aplicação de suas demonstrações. Diante dessa abstração, o aluno que não tem prévios conhecimentos em matemática, é prejudicado e assim, acaba trazendo mais conflito para o desenvolvimento do seu conhecimento.

O professor algebrista, geralmente cria problemas contraditórios, separados de quaisquer objetivos práticos, procura por meios complicadíssimos resolver problemas que têm soluções fáceis e conclusões úteis, fazendo com que a criança não desenvolva o menor interesse em estudar.

De acordo com os PCNs

Essa prática de ensino tem se mostrado ineficaz, pois a reprodução correta pode ser apenas uma simples indicação de que o aluno aprendeu a reproduzir alguns procedimentos mecânicos, mas não aprendeu e não sabe utilizá-lo em outros contextos (PCNs, , 1998, p.37)

Diante às necessidades dos alunos em ampliar uma ligação com a matemática, de maneira atrativa, para conseguir um resultado eficaz em seu aprendizado, é essencial para o estudante expandir a disposição e o desejo pela matemática e saber perceber um problema, buscando e selecionando informações para resolvê-lo, e ao mesmo tempo, tomar decisões, e assim sua chance será maior para a interação com as tecnologias do dia a dia, fazendo com que tenha mais facilidade para identificar e resolver novos problemas.

Diversos estudantes têm dificuldades de aprendizagem em matemática e acreditam que essa disciplina é uma "tortura". As dificuldades envolvidas que permeiam o ensino e a aprendizagem e os déficits ocasionados pelo desempenho escolar abaixo do esperado tornaram a matemática uma disciplina que gera inquietação. Provocando inúmeras dúvidas sobre o seu ensino e sua aprendizagem.

$\mathrm{Na}$ aprendizagem da matemática, diferentes habilidades cognitivas são requeridas, como: uso da informação numérica; atenção e concentração; astúcias espaços - temporais; competências do raciocínio lógico, entre outras. A despeito desses elementos, a dificuldade na matemática está 
relacionada à maneira como ela é tratada; como o estratagema didático é utilizado no seu processo de ensino - aprendizagem e as situações emocionais que podem interferir em seu desempenho.

O cerne da matemática reside na compreensão de seus elementos e processos, envolvendo um esforço constante, tanto do professor, quanto do aluno. As crianças não aprendem com informação destituída de significado. Se as crianças se concentram nas relações em vez de métodos que desenvolvam a memória, sua aprendizagem tornar-se-á mais significativa, duradoura e satisfatória.

É fundamental o entendimento de que para a aprendizagem ser significativa é preciso proporcionar tempo àquele que aprende, ou seja, ao sujeito aprendiz. Por isso, a matemática deve ser ensinada, buscando a compreensão gradativa de seus conteúdos. É preciso entender a sequência de cada etapa para seguir em frente. O tempo propício para a reformulação do pensamento, para acrescentar novas aprendizagens às já interiorizadas.

\section{DADOS REVELADOS PELA PESQUISA}

Ao estabelecermos as categorias de análise, não objetivamos "encaixar", "rotular" ou “engessar" os sujeitos em determinados estereótipos, papéis, modos ou modelos específicos que sejam fechados e estreitos em relação aos seus modos de ser ou agir. O que buscamos são aproximações manifestadas por meio da análise de suas falas, em relação às questões que envolvem nossa problemática e que tem implicações sobre como ocorrem às práticas docentes.

$\mathrm{Na}$ diferente de tantas outras pesquisas semelhantes à nossa, ressaltamos ainda a dificuldade em analisar as concepções dos professores participantes da investigação, principalmente quando isso se remete à perspectiva de investigar quais são os pressupostos teóricos que formam direta ou indiretamente seu ideário pedagógico. Assim, mesmo que esse estudo não tenha tido como objetivo classificar os professores numa tendência ou outra, e muito menos julgá-los incisivamente por apresentar, aparentemente, algumas práticas e concepções fundamentadas em um ou outro modelo educacional, foi possível constatarmos o quanto a tarefa da análise dos dados é angustiante, visto que não sabemos se estamos sendo justos ou não em relação à nossa interpretação das percepções dos sujeitos.

Buscamos investigar e compreender as concepções dos professores, bem como as suas práticas ao se depararem com as dificuldades de aprendizagem em matemática de seus alunos levando em consideração duas categorias de análise distintas, sendo elas: Perspectiva Tradicional do ensino da Matemática e Perspectiva Contemporânea de Educação Matemática.

Para compreendermos as concepções dos professores relacionados às Dificuldades de Aprendizagem e Dificuldades de Aprendizagem em Matemática, aplicamos questionários, realizamos entrevistas e observamos as práticas desses educadores. 
Ao indagarmos a professora $\mathbf{P a o l a}^{2}$ a respeito de como define dificuldades de aprendizagem, ela pontua que diversos fatores podem desencadear uma dificuldade no aluno. Em sua visão tais fatores podem estar relacionados a "problemas comportamentais, sociais, neurológicos, emocionais". Observamos certa dificuldade da professora ao responder a essa questão. Pois, não perguntamos o quê pode desencadear a dificuldade de aprendizagem, mas sim, o que é dificuldade de aprendizagem. Autores como Smith e Strick (2001); Coll, Palacios e Marchesi (1995) utilizam o termo dificuldade de aprendizagem para referir-se a distúrbios, entendendo a Dificuldade de Aprendizagem como qualquer dificuldade observável no aluno em acompanhar o ritmo de aprendizagem da turma.

Observamos o posicionamento parecido em sua entrevista. Quando solicitamos que ela respondesse o que é dificuldade de aprendizagem, a educadora pontuou que "vai de cada aluno (...) eu acho que já vem desde lá da base familiar”. Novamente a educadora apresenta uma possível causa para a dificuldade de aprendizagem não revelando a sua opinião sobre o quê concebe como dificuldade de aprendizagem. Todavia, a respeito das possíveis causas da dificuldade de aprendizagem, Fernandez (1991) acredita que pode estar relacionada à estrutura familiar, sendo assim, na visão do autor, uma família desestruturada pode sim levar um estudante a ter dificuldades de aprendizagem.

Patrícia, Lúcia e Meire concebem que as dificuldades de aprendizagem dos alunos ocorrem quando estes não conseguem aprender, mesmo depois de diversas explicações e realizações de exercícios. Essa constatação é reforçada na entrevista, quando Lúcia relata que "é a dificuldade de entender aquilo que é passado, de assimilar os conteúdos, de acompanhar o processo da turma que ela (a criança) está inserida”. Meire revela que é "tudo aquilo que você não tem a compreensão do que está sendo trabalhado".

A professora Patrícia se contradiz durante a entrevista ao afirmar que "eu caracterizo dificuldade em aprender ou ele não interessado, ou ele tem algum problema”. Com este depoimento a professora Patrícia revela um entendimento de dificuldade próximo aos dos autores Smith e Strick (2001); Coll, Palacios e Marchesi (1995), quando estes utilizam o termo dificuldade de aprendizagem para referirem-se a diversos fatores que podem causar as dificuldades de aprendizagem.

A professora Maria defende que as dificuldades na aprendizagem são transtornos passíveis de superação, e que podem ser amenizadas com o passar do tempo. A mesma concepção é revelada por Charlot (1997 apud Chabanne, 2006, p. 17), quando o autor define esse intervalo em que o estudante está com dificuldade pode ser entendido como um tempo de "experiência que o aluno vive $e$ interpreta”. Assim, esta dificuldade resume-se a um estado momentâneo na aprendizagem do educando. Porém, contraditoriamente em entrevista, a professora Maria declara que “(...) dificuldade

\footnotetext{
${ }^{2}$ Os nomes atribuídos aos sujeitos são fictícios, pois procuramos preservar a identidade dos mesmos.
} 
de aprendizagem é quando o aluno é apático, não consegue resolver o que é proposto e também não tem interesse naquilo que é proposto para ele fazer. Neste caso, observamos que para a professora a falta de motivação por parte do aluno diante de uma aula possivelmente entediante pode caracterizarse como dificuldade de aprendizagem.

A professora Lilian apresenta respostas evasivas, portanto, consideramos muito frágil sua concepção em relação à definição de Dificuldades de Aprendizagem.

As professoras Patrícia, Paola, Lúcia, Lilian e Maria dizem que as maiores dificuldades ocorrem na aprendizagem de matemática. A seguir citamos os seus relatos com a finalidade de confirmar nossas constatações:

Muito, inclusive eu tenho até assim, o relato de uma mãe, que todo início de ano para ela é uma tortura ter que mandar a filha para a escola e ela sempre falava assim "Mãe e a matemática?" e a mãe respondia assim "A matemática vai estar lá e a professora estará lá para te ajudar e eu aqui para tentar te ajudar também." Esse ano graças a Deus ela superou e a mãe ficou muito emocionada e veio até a mim (Patrícia).

Tanto em matemática quanto em linguagem. (Paola)

Em aprender matemática e em algumas áreas sim. (Lúcia)

Essas crianças com dificuldades, eles não tinham noção o que era multiplicação, o que era divisão e o que era subtração. (Lilian).

Alguns apresentam em matemática. (Maria).

Ressaltamos ainda que as professoras acima citadas argumentam que as dificuldades de aprendizagem em matemática se restringem as operações elementares (adição, subtração, divisão e multiplicação), visto que elas valorizam de forma exagerada o cálculo mecânico, com ênfase no algoritmo.

Na visão da professora Meire, os alunos não aprendem pelo fato de serem descompromissados, aliás, a educadora pontua que não são apenas os estudantes que revelam falta de compromisso, mas também, seus familiares. E ainda em entrevista, ela relata que: “não é só na matemática (que os educandos possuem dificuldades) como também nas áreas de Humanas. Os alunos não têm a compreensão, não tem leitura”. (Meire).

Em entrevistas, as professoras Meire e Patrícia, corroboram este entendimento ao apontarem como causas das dificuldades de aprendizagem a falta de participação da família. Podemos verificar a veracidade desta afirmação por meio dos seus relatos: 
(...) eu acredito que é a falta de acompanhamento dos pais, dos familiares, porque só o professor em sala de aula é impossível sanar todas as dificuldades (Patrícia).

(...) a família deve estar auxiliando esse aluno nessa dificuldade que ele tem. As atividades que vão para casa para poder produzir, porque muitas vezes só com os professores essa criança não aprende (Meire).

Assim, as falas das professoras Paola, Patrícia, Lúcia e Meire, apontam que a falta de participação da família no processo escolar é a principal causa das dificuldades apresentada pelos estudantes. No entanto, somos cientes de que a grande responsabilidade em promover a aprendizagem dos alunos é do professor. A família, também, contribui nesse processo, mas, é importante evidenciar que os papéis que cada um desenvolve são diferentes, cabe ao educador ensinar e à família acompanhar o processo educacional de seus filhos. Sobre esta questão, Munhoz (2004, p.180) citado por (SAMPAIO, 2009, p.69) declara que "é observando a interação existente entre os membros da família que podemos entender como ocorre a circulação do conhecimento e o acesso à aprendizagem (...)”. Isto é, se não há interação familiar, possivelmente a criança apresentará problemas de aprendizagem.

A professora Lilian acredita que a falta de conhecimentos dos anos anteriores causa dificuldades de aprendizagem em matemática. Isto é, em sua visão, todo conhecimento é acumulativo e a criança necessita de base para ter maturidade ao solucionar/realizar suas atividades escolares. Este entendimento também é revelado por Scoz $(1994$, p.72) quando o autor ressalta que "a criança errou por não possuir a estrutura de pensamento necessária para compreender a tarefa", causando assim as dificuldades de aprendizagem.

Notamos na resposta da professora Maria, que os problemas comportamentais e emocionais são os que causam, as dificuldades. Referente a este assunto, Smith e Strick (2001, p.72) relatam que "as crianças com dificuldades de aprendizagem podem ter uma ampla variedade de problemas comportamentais", estes mesmos autores ainda defendem que os primeiros sinais de um problema de aprendizagem são os problemas comportamentais em sala e mudança de humor em casa.

As professoras Maria, Lúcia e Paola apresentam respostas evasivas, portanto consideramos frágeis suas concepções a respeito das causas das dificuldades de aprendizagem em matemática.

\section{CONSIDERAÇÕES FINAIS}

Esclarecemos que as considerações aqui apresentadas tratam-se apenas de um olhar, isto é, referem-se a julgamento bem particular de nossa parte, segundo as nossas concepções e o nosso entendimento dos referenciais teóricos utilizados. Sendo assim, não pretendemos dizer que as análises realizadas não admitem outros olhares, pois não consideramos as situações e assuntos aqui discutidos como resultado final e conclusivo. Somente buscamos por intermédio de realização de nossa 
investigação, promover espaços motivadores de possíveis reflexões que possam propiciar mudanças significativas nas práticas dos professores que atuam em turmas de $4^{\text {os }}$ ano do Ensino Fundamental.

$\mathrm{Na}$ verdade, percebemos que a maioria dos nossos sujeitos não pôde ter suas concepções compreendidas apenas no interior do modelo tradicional ou do modelo contemporânea. Elas aparecem mais fortemente em um estado de transição, ora voltadas ao modelo tradicional, ora ao modelo contemporâneo.

Em resposta ao problema de pesquisa, consideramos que as concepções nas falas das professoras transitam pelas perspectivas tradicionais e contemporânea de ensino, porém há uma maior tendência ao modelo contemporâneo. Contudo, as concepções reveladas nas práticas dos professores com exceção das educadoras Maria e Paola, que apresentam percepções próximas do modelo contemporâneo.

Os relatos das angústias em relação às dificuldades de aprendizagem em matemática evidenciam-se que as professoras não possuem uma concepção bem definida destas dificuldades e dos fatores que as desencadeiam. Boa parte das educadoras parece não perceber que sua prática em sala de aula pode se incluir entre os principais fatores causadores destas dificuldades.

Entendemos que a dinâmica do processo de construção de uma nova concepção é desencadeada pelo conflito de ideias, pelo desequilíbrio e a necessidade de "equilibração". Durante nossa investigação, notamos que os professores pesquisados encontram-se neste conflito. Neste sentido, um educador comprometido com as aprendizagens de seus alunos, deve estar sempre buscando respostas para as situações para as situações/questões que se apresentam em sala de aula, e essa compreensão depende de esforço intelectual que perpassa por aprofundamento em relação às teorias de aprendizagem e das especificidades dos conhecimentos relativos à sua área de atuação.

Realçamos que nossas indagações ainda não foram completamente respondidas, entendemos que ainda há muito a ser estudado sobre o assunto, porém nosso trabalho revelou que há possíveis problemas nas práticas pedagógicas relacionadas às dificuldades de aprendizagem em matemática. Tal observação não se constata apenas por meio dos instrumentos utilizados para coleta de dados, mas também pelos relatos angustiados dos professores que participaram da pesquisa.

Após o levantamento efetuados, sugerimos a Secretaria de Estado de Educação via Centros de Formação - $\mathrm{CEFAPRO}^{3}$ s, em pareceria com as universidades, promovam formações continuadas para discutir com mais profundidade sobre as dificuldades de aprendizagem, suas causas e diagnósticos.

\footnotetext{
${ }^{3}$ Centros de Formação e Atualização dos Profissionais da Educação Básica mantidos pela Secretaria de Estado de Educação de Mato Grosso
} 
Gostaríamos, ainda de ressaltar que somos professores efetivos da rede estadual de ensino, fazemos parte do contexto deste trabalho e, em diversos momentos nos reconhecemos nas falas e nas práticas dos sujeitos, ora numa perspectiva tradicional, ora numa perspectiva contemporânea, diante das mesmas dúvidas e sentindo as mesmas inquietações.

Com a realização da pesquisa foi possível refletir sobre nossa própria dinâmica pessoal no processo de construção dos conhecimentos para docência em matemática, o que certamente contribuiu para o desenvolvimento profissional e pessoal. Estamos cientes que não somos mais ou mesmos. Crescemos e avançamos. Mas, também temos certeza de que ainda existe um grande caminho para percorrermos e assim alcançar uma educação de qualidade. 


\section{REFERÊNCIAS}

ALMEIDA. S. F. \& Col. (1995) Concepções e práticas de psicólogos acerca das aprendizagem. Psicologia: teoria e pesquisa. 11 (2), $117-134$.

BRASIL. Secretaria de Educação Fundamental. Parâmetros Curriculares Nacionais: Matemática /Secretaria de Educação Fundamental. Brasília: MEC /SEF, 1998.

BRUNELli, A. O. Concepções de EJA, de ensino e de aprendizagem de matemática de formadores de professores e suas implicações na oferta de formação continuada para docentes de matemática. / Dissertação (Mestrado em Educação). - Instituto de Educação, Universidade Federal de Mato Grosso - UFMT, Cuiabá - MT, 2012.

CHABANNE. J. L. Dificuldade de aprendizagem: um enfoque inovador do ensino escolar. Traduzido por Regina Rodrigues. São Paulo: Ática, 2006.

CHARLOT, Bernard. Da relação com o saber: elementos para uma teoria. Trad. Bruno Magne. Porto Alegre: Artmed, 2000.

COLL, C. PALACIOS, J. MARCHESI, A. Desenvolvimento psicológico e educação: necessidades educativas especiais e aprendizagem escolar. Porto Alegre: Artes médicas, 1995.

CORREIA, L. M., \& MARTINS, A. P. L. Dificuldades de aprendizagem. O que são, como entendelas? Porto: Porto Editora, 1998.

CORSINI, C. F. Dificuldade de Aprendizagem: representações sociais de professores e alunos. Dissertação de Mestrado - PUCCAMP.

FERNÁNDEZ, A. A inteligência aprisionada: abordagem psicopedagógica clínica da criança e sua família. Porto Alegre: Artmed, 1991.

GARCÍA, J. N. Manual de dificuldades de aprendizagem: linguagem, leitura, escrita e matemática. Porto Alegre: Artes Médicas, 1998. Tradução de: Jussara Haubert Rodrigues.

MUNHOZ, M. L. P. Educação e família em uma visão psicopedagógica sistêmica. In Psicopedagogia: contribuições para a educação pós moderna. Petrópolis, RJ: Vozes; São Paulo: ABPp, 2004.

PATTO, M. H. S. A produção do fracasso escolar: história de submissão e rebeldia. São Paulo: Casa do Psicólogo, 1999.

SADOVSKY, P. Falta de fundamentação didática no ensino da matemática. Nova Escola. São Paulo, Ed. Abril, Jan/Fev. 2007.

SAMPAIO, S. Dificuldade de aprendizagem - a psicopedagogia na relação sujeito, família e escola. Rio de Janeiro, Ed. Wak, 2009.

SANCHEZ, Jesús Nicasio Garcia. Dificuldade de Aprendizagem e Intervenção Pedagógica. Porto Alegre: Artmed, 2004. 
SCOZ, B. Psicopedagogia e a realidade escolar, o problema escolar e de aprendizagem. Petrópolis: Vozes, 1994.

SMITH, C; STRICK, L. Dificuldades de Aprendizagem de A a Z: um guia completo para pais e educadores. Porto Alegre: Artmed, 2001. Tradução de Dayse Batista.

TIBALLI, E. F. O fracasso escolar no pensamento educacional brasileiro. São Paulo: Pontífica Universidade Católica de São Paulo, 1998. Tese de Doutorado.

VITTI, C. M. Matemática com prazer, a partir da história e da geometria. $2^{\text {a }}$ Ed. Piracicaba - São Paulo, Editora UNIMEP, 1999. 